\title{
NVMO-congres 2008
}

\section{BSL-prijzen toegekend}

Tijdens het afgelopen NVMO-congres te Noordwijkerhout zijn opnieuw de door Bohn Stafleu Van Loghum ingestelde prijzen uitgereikt voor de beste Wetenschappelijke Paper, de beste 'Gewone' Paper en de beste Posterpresentatie.

\section{Samenstelling van de jury:}

- Prof. dr. Jan C.C. Borleffs, voorzitter voorafgaand aan en op eerste dag van het congres (UMC Groningen),

- Dr. Cornelis T. Postma, waarnemend voorzitter tweede dag van het congres (UMC St Radboud Nijmegen),

- Dr. Kristin Hendrickx (Universiteit van Antwerpen),

- Dr. Hans Hoekstra (Jeroen Bosch Ziekenhuis, Den Bosch),

- Dr. Marlies Schijven (UMC Utrecht),

- Gor Khatchikyan, geneeskundestudent (Universiteit van Amsterdam).

Door omstandigheden was de voorzitter, prof. dr. Jan Borleffs, genoodzaakt het voorzitterschap tijdens het congres over te dragen aan de waarnemend voorzitter dr. Cornelis Postma die ook de prijsuitreiking op zich heeft genomen.

De jury heeft zich al voor het congres vol enthousiasme aan haar taak gezet.

\section{Gevolgde procedure}

Op basis van de onderstaande criteria werden door de juryleden alle 86 abstracts van wetenschappelijke en gewone papers naast alle posterabstracts gelezen en volgens onderstaande criteria beoordeeld.
De volgende criteria werden bij de beoordeling van de abstracts gehanteerd:

1) Beoordeling op inhoud:

- originaliteit

- relevantie van de vraagstelling voor het onderwijs

- lokaal niveau overstijgend

- bij een paper: de sterkte van het onderzoeksdesign

2) Beoordeling op het abstract:

- het abstract dient te voldoen aan de richtlijnen:

paper: probleemstelling, methode/ opzet, resultaten en conclusie, discussie, maximaal 2 literatuurverwijzingen

poster: probleemstelling, methode/ opzet, resultaten/ervaringen/evaluaties, conclusies/tips voor de praktijk

3) Beoordeling van de kwaliteit van de paperpresentatie zelf:

- de presentatie wordt beoordeeld via een checklist door meerdere juryleden

- de presentatie dient van goede kwaliteit te zijn wat betreft opbouw en stijl

- de presentator houdt zich aan de tijd en heeft goed contact met de zaal

- de presentator voert een levendig debat bij het beantwoorden van de vragen

4) Beoordeling van de poster:

- een poster dient uitnodigend te zijn

- een poster dient van goede kwaliteit te zijn wat betreft opbouw, layout, lettertype c.q. leesbaarheid en kleurstellingen 


\section{Nominaties}

De juryleden selecteerden op basis van de eerste twee criteria ieder 10-15 abstracts die in aanmerking zouden kunnen komen voor een prijs. Op basis van deze selecties werd er door de voorzitter een definitieve selectie gemaakt. Abstracts die door meerdere juryleden waren geselecteerd werden opgenomen in deze lijst met genomineerden. De lijst met genomineerden bestond uit 5 wetenschappelijke papers, 4 gewone papers en 3 posters. Deze lijst werd tijdens het diner op donderdagavond door de waarnemend juryvoorzitter bekend gemaakt.

De juryleden hadden ieder een aantal presentaties toegewezen gekregen die zij ter beoordeling dienden bij te wonen. Iedere presentatie werd door minimaal twee juryleden bijgewoond en beoordeeld op basis van de criteria genoemd onder 3 .

De genomineerde posterpresentaties werden door alle juryleden beoordeeld op basis van de criteria genoemd onder 4 .

Tijdens het congres vergaderde de jury enige malen over de jurering en vrijdag na het laatste blok over de definitieve toekenning van de prijzen.

\section{Toegekende prijzen}

De prijzen werden als volgt toegekend:

Prijs voor de beste Wetenschappelijke paper:

L. Urlings-Strop et al. (Erasmus MC). Prestaties van geselecteerde versus ingelote studenten in de preklinische en klinische fase.

De jury kwam tot een unaniem besluit bij de toekenning van deze prijs. Het abstract heeft een intrigerend onderwerp dat op een duidelijke en eenduidige wijze werd uiteengezet. Het onderwerp van studie is controversieel en alleen onderzoek naar de waarde van de selectie en de selectiecriteria kan duidelijkheid brengen over de betekenis hiervan voor de studie geneeskunde. De gepresenteerde studie draagt hiertoe zeker bij. De resultaten werden op een deskundige, betrokken en enthousiaste wijze naar voren gebracht hetgeen de juryleden versterkte in hun waardering. Een verdiende prijs voor dit fraaie onderzoek en de heldere presentatie.

\section{Prijs voor de beste Paper:}

E. Pelgrim et al. (UMC St Radboud). Inter-beoordelaarsbetrouwbaarheid tussen simulatiepatiënten en tussen simulatiepatiënten en artsen bij een Objective Structured Clinical Examination (OSCE).

De jury was ook over de toekenning van deze prijs zeer eensgezind over inhoud en presentatie. Een heldere en duidelijke presentatie over een goed gestructureerd en gedefinieerd onderzoek. Meer evidence aangaande de betrouwbaarheid van simulatiepatiënten bij high stakes examens is zonder meer belangrijk en deze studie draagt daartoe zeker bij.

\section{Prijs voor de beste Poster:}

M. Tepper et al. (UMC Groningen, Sint Maartenskliniek Nijmegen, Muhimbili Hospital Dar es Salaam). Leren over grenzen. DE SSART, een wereldwijd gebruikte screening op slikstoornissen aangepast voor gebruik in ontwikkelingslanden.

Deze poster was de weergave van een voorbeeld van een goed doordacht en opgezet project met een heel goede uitstraling wat betreft internationale samenwerking vooral met een ontwikkelingsland. De poster werd met groot enthousiasme en deskundigheid gepresenteerd. De poster was ook aantrekkelijk vormgegeven hetgeen uitnodigde om van de boodschap kennis te nemen.

Elke prijswinnaar ontving op de slotzitting een bos bloemen en een boekenbon ter waarde van 150 euro, te kiezen uit het aanbod van BSL. De winnaar van de prijs voor de beste wetenschappelijke paper ontving tevens een door de voorzitter van het congres, dr Benno Bonke, ter beschikking ge- 
steld bijzonder fraai kunstwerk. De auteurs werden uitgenodigd een artikel aangaande de in het abstract beschreven onderwerpen ter publicatie in het TMO voor te bereiden en ontvangen een uitnodiging voor één gratis deelname aan het NVMO-congres 2009. De abstracts van de genomineerden en prijswinnaars worden gepubliceerd in het Tijdschrift voor Medisch Onderwijs.

Cornelis T. Postma,

namens de juryleden

\section{Genomineerden Wetenschapelijke papers}

De voor-en nadelen van contacten met echte patiënten en simulatiepatiënten in het medisch onderwijs: een focusgroep onderzoek

\section{Bokken, J.J. Rethans, A. Scherpbier, C. van der Vleuten}

Probleemstelling: Patiëntcontacten, zowel met echte patiënten als met simulatiepatiënten, zijn onmisbaar in de huidige artsenopleiding. Contacten met echte patiënten en simulatiepatiënten hebben verschillende voor- en nadelen, vanuit het perspectief van docenten, patiënten en studenten. ${ }^{1,2}$ Vanuit het perspectief van de student zijn er studies gedaan naar de tevredenheid van studenten met (simulatie)patiëntcontacten, al dan niet vergeleken met meer traditionele onderwijsvormen zoals colleges of rollenspel. Er zijn echter weinig studies die de waarde van echte patiëntcontacten en simulatiepatiëntcontacten vergelijken vanuit het perspectief van de student. ${ }^{1}$ Het doel van dit onderzoek was 1) het inventariseren van de opvattingen van studenten ten aanzien van de voor- en nadelen van contacten met echte patiënten en simulatie- patiënten in de preklinische fase en 2) het geven van suggesties ter verbetering van de inzet van echte patiënten en simulatiepatiënten in het medisch onderwijs.

Methode: Er werden vijf focusgroepbijeenkomsten gehouden met in totaal 38 vierde- en vijfdejaars studenten geneeskunde. De discussie werd semigestructureerd aan de hand van vooraf opgestelde vragen. De discussie werd opgenomen en uitgeschreven en een samenvatting werd voorgelegd aan de deelnemers ter goedkeuring. Het transcript werd onafhankelijk gecodeerd door twee onderzoekers. Bij verschil van mening werden de codes bediscussieerd tot overeenstemming werd bereikt. De codes kwamen grotendeels overeen met de vragen die bediscussieerd werden in de groep.

Resultaten: In het algemeen vonden studenten de echte patiëntcontacten leerzamer dan de simulatiepatiëntcontacten. Studenten benoemden echter ook enkele voordelen van simulatiepatiënten ten opzichte van echte patiënten. Studenten vonden simulatiepatiëntcontacten nuttig ter voorbereiding op echte patiëntcontacten en ze versterkten het zelfvertrouwen van de student. Tevens werden de simulatiepatiëntcontacten nuttig gevonden voor het oefenen van 'intiem' onderzoek, zoals het gynaecologisch onderzoek en het urogenitaal onderzoek, en voor het krijgen van constructieve feedback. Een nadeel van simulatiepatiëntcontacten is de sterke nadruk op communicatievaardigheden in plaats van op medische vaardigheden zoals het lichamelijk onderzoek. In tegenstelling tot wat werd gevonden in eerder onderzoek $^{1}$ vonden studenten het nemen van een time-out gemakkelijker in contacten met echte patiënten en vonden ze echte patiëntcontacten authentieker dan simulatiepatiëntcontacten. 
Discussie: Studenten beschouwen zowel de contacten met echte patiënten als die met simulatiepatiënten als onmisbaar tijdens de artsenopleiding, elk met unieke voor- en nadelen. Op basis van de gevonden voor- en nadelen worden suggesties gedaan ter verbetering van de inzet van echte patiënten en simulatiepatiënten in de preklinische fase van het medisch onderwijs, zoals het inzetten van simulatiepatiënten voorafgaand aan contacten met echte patiënten en het toenemend integreren van medische vaardigheden in de simulatiepatiëntcontacten.

\section{Literatuur}

1. Bokken L, Rethans JJ, Scherpbier A, Van Der Vleuten C. Strengths and weaknesses of simulated and real patients in the teaching of skills to medical students: a review. Simulation in Health Care. In press.

2. Collins JP, Harden RM. Real patients, simulated patients and simulators in clinical examinations. Med Teach 1998;20:508-21.

Correspondentieadres:

Dr. L. Bokken, Universiteit Maastricht, Vakgroep Onderwijsontwikkeling en Onderzoek, postbus 616, 6200 MD Maastricht.E-mail: l.bokken@educ.unimaas.nl

De ervaren leerzaamheid van echte patiënten en simulatiepatiënten in het medisch onderwijs: een gerandomiseerd experiment

L. Bokken, J.J. Rethans, A. Scherpbier, C. van der Vleuten

Probleemstelling: Patiëntcontacten, zowel met echte patiënten als met simulatiepatiënten, zijn niet meer weg te denken uit de huidige artsenopleiding. Slechts enkele studies hebben de leerzaamheid van echte patiëntcontacten vergeleken met simulatiepatiëntcontacten. ${ }^{1}$ De meeste studies, die zich richtten op verschillen in prestatie van studenten op een OSCE, vonden geen verschil. Desondanks geven studenten regelmatig aan dat er een verschil is in de leerzaamheid van echte patiëntcontacten en simulatiepatiëntcontacten. Het doel van dit experiment is 1) nagaan welk contact (echte patiënt of simulatiepatiënt) wordt ervaren als het meest leerzaam door studenten in de preklinische fase en 2) nagaan welke variabelen een rol spelen bij de ervaren leerzaamheid.

Methode: Er werd een experiment uitgevoerd waarbij 163 eerstejaars geneeskunde studenten gerandomiseerd werden in twee groepen. Een groep studenten $(\mathrm{N}=61)$ kreeg een contact met een echte patiënt en een andere groep $(\mathrm{N}=102)$ een regulier simulatiepatiëntcontact. Er werd gebruik gemaakt van zowel kwantitatieve (vragenlijsten) als kwalitatieve (focusgroepbijeenkomsten) methoden om de ervaren leerzaamheid van het contact te meten. De vragenlijsten werden samengesteld aan de hand van literatuur en suggesties van experts, studenten en docenten, resulterend in een vragenlijst voor studenten (36 items) en een voor docenten (15 items).

Resultaten: Studenten gaven een hoog cijfer voor de algemene leerzaamheid van de echte patiëntcontacten en de simulatiepatiëntcontacten (respectievelijk 7.4 en 7.2 op een 10-punts schaal). Er werden meerdere significante verschillen gevonden tussen de studentbeoordelingen van de echte patiëntcontacten en de simulatiepatiëntcontacten. Studenten vonden in vergelijking met simulatiepatiënten de echte patiënten minder geschikt voor het oefenen van communicatievaardigheden (ES 0.65) en de feedback van de echte patiënten minder relevant (ES 0.69). Daarnaast waren studenten meer benieuwd afwijkingen te vinden bij lichamelijk onderzoek bij echte patiënten (ES 0.62). De focusgroepen leverden verklaringen op voor veel van de gevonden verschillen. 
Studenten vonden de echte patiënten authentieker dan de simulatiepatiënten. De simulatiepatiënten waren echter beter op de hoogte van de opzet van de contacten en gaven specifieke feedback. Ook lag de nadruk bij simulatiepatiëntcontacten meer op communicatievaardigheden in plaats van op medische vaardigheden zoals het lichamelijk onderzoek.

Discussie: Studenten beschouwen authenticiteit als een groot voordeel van echte patiëntcontacten. De moeizame werving en selectie van geschikte patiënten is echter een groot nadeel van het gebruik van echte patiëntcontacten. Simulatiepatiënten hebben een aantal voordelen boven echte patiënten, zoals de betere mogelijkheden voor studenten om de structuur in een consult te oefenen en de betere feedback aan studenten. De keuze voor simulatiepatiëntcontacten of echte patiëntcontacten in het medisch onderwijs is afhankelijk van de fase in het curriculum, het doel van het contact en de docent die het contact begeleidt.

\section{Literatuur}

1. Bokken L, Rethans JJ, Scherpbier A, Van Der Vleuten C. Strengths and weaknesses of simulated and real patients in the teaching of skills to medical students: a review. Simulation in Health Care. In press.

Correspondentieadres:

Dr. L. Bokken, Universiteit Maastricht, Vakgroep Onderwijsontwikkeling en Onderzoek. Postbus 616, 6200 MD Maastricht.E-mail: l.bokken@educ.unimaas.nl

Prestaties van geselecteerde versus ingelote studenten in de preklinische en klinische fase

L.C. Urlings-Strop, A.P.N. Themmen, T. Stijnen, T.A.W. Splinter

Inleiding: Het aantal beschikbare plaatsen voor geneeskunde is kleiner dan het aantal gegadigden, daarom heeft voor toelating altijd een vorm van selectie plaats. Wereldwijd worden cijfers behaald op de middelbare school voorspellend gevonden voor studeerprestaties tijdens de pre-klinische fase, echter niet voor de klinische fase. ${ }^{1}$ De medical college admission test is wel een redelijke voorspeller voor studeerprestaties in de klinische fase. ${ }^{2}$ Het Erasmus MC is in 2001 gestart met een gecontroleerd experiment van selectieve toelating van scholieren die het VWO hebben afgerond. Het doel van deze studie is na te gaan of de geselecteerde studenten andere studeerprestaties vertonen dan ingelote studenten.

Methode: De selectieprocedure bestaat uit twee fasen. De eerste fase berust op kwaliteit en kwantiteit van extracurriculaire activiteiten. Kandidaten die hierop bovengemiddeld scoorden ten opzichte van de anderen werden toegelaten tot fase twee waarin vijf cognitieve toetsen plaats hadden. Kandidaten met maximaal één onvoldoende en gemiddeld een voldoende werden toegelaten. Van de cohorten 20012004 zijn studeersnelheid (aantal ECTS/ jaar), gemiddeld cijfer van de eerste tentamenpogingen en extracurriculaire activiteiten in de pre-klinische fase gemeten. Uitval is gedefinieerd als minder dan 60 ECTS na de eerste 2 studiejaren en nominaal als 60 ECTS per jaar. Verder is het aantal studenten bepaald dat voor $31 / 3 / 2008$ is gestart met de klinische fase en het cijfer behaald voor de eerste drie co-schappen.

Voor verschillen tussen groepen is een Mantel-Haenzsel stratificatie-test gebruikt met correcties voor lotingscategorie en cohort en Student-t-toets. Effectgrootte is uitgedrukt in Cohen's.

Resultaten: Gegevens zijn afkomstig van 389 geselecteerde en 938 ingelote studenten. Het relatieve risico op uitval in de eerste twee studiejaren lag voor geselecteerde 
studenten 2,5 keer lager dan voor ingelote studenten $\left(\chi^{2}(1)=14.68, p=0.000\right)$. Behalve voor cohort 2001 was het percentage nominaal studerende studenten én het gemiddelde tentamencijfer voor beide groepen gelijk. Van de geselecteerden volgden $19,2 \%$ naast hun studie een tweejarige researchmaster-opleidingen of een andere studie of waren actief in bestuursfuncties, tegenover 9,6\% van de ingelotenen. Inmiddels is $39,1 \%$ van de geselecteerde en $51.1 \%$ van de ingelote studenten gestart met de klinische fase $\left(\chi^{2}(1)=0.71\right.$, $p=0.401)$. Van deze groep hebben 91 geselecteerde en 339 ingelote studenten drie of meer cijfers behaald voor de klinische fase. De geselecteerden haalden voor deze drie co-schappen gemiddeld een 7.97, de ingelote studenten een $7.79(t(428)=3.781$, $p=0.000$, Cohen's $\Delta=0.42$ ).

Conclusies: Dit is wereldwijd de eerste gecontroleerde studie waarin is aangetoond dat VWO-scholieren geselecteerd kunnen worden op eigenschappen die geassocieerd zijn met betere prestaties tijdens de studie geneeskunde, anders dan hun eindexamencijfer.

Geselecteerde studenten vertonen aanzienlijk minder uitval, voeren vaker extracurriculaire activiteiten uit en behalen hogere cijfers in de klinische fase. Geselecteerde studenten stromen minder snel door naar de klinische fase vanwege deelname aan extracurriculaire activiteiten.

Vervolgvraag is welke persoonskenmerken aan de gevonden verschillen ten grondslag liggen.

\section{Literatuur}

1. Salvatori P. Reliability and validity of admissions tools used to select students for the health professions. Advances in Health Sciences Education $2001 ; 6: 1$ 59-175

2. Koenig JA, Sireci SG, Wiley A. Evaluating the Predictive Validity of MCAT Scores across Diverse Applicant Groups. Academic Medicine 1 998;73 (10):1095-1106.
Correspondentieadres:

L.C. Urlings-Strop, Erasmus MC, Opleidingsinstituut Geneeskunde, kamer Ff 2.10, postbus 2040, 3000 CA

Rotterdam. E-mail: l.urlings-strop@erasmusmc.nl

Verschillen qua instroomkenmerken, studeergedrag en studieprestaties tussen studenten die slecht(er) presteren in de propedeuse

K.M. Stegers-Jager, G.J.A. Baars, T.A.W. Splinter

Probleemstelling: Wereldwijd heeft het verminderen van studie-uitval en het verhogen van de studeersnelheid een hoge prioriteit, ook voor medische opleidingen. Uitval kan gezien worden als het resultaat van een mismatch tussen de student en de leeromgeving en is het hoogst in de propedeuse $^{1}$. Doel van deze studie is het identificeren en karakteriseren van zogeheten students-at-risk tijdens het eerste jaar, zodat in de toekomst adequate interventies ontwikkeld kunnen worden om deze studenten te remediëren. Op grond van de literatuur zijn zowel instroomkenmerken van studenten, zoals geslacht, etniciteit en gemiddeld eindexamencijfer, ${ }^{1}$ als studieprestaties tijdens de eerste maanden ${ }^{2}$ meegenomen.

Methode: Op basis van studievoortganggegevens van 1793 studenten van vijf opeenvolgende cohorten (2001- 2005) is met behulp van logistische regressie-analyses een prognostisch model ontwikkeld. Afhankelijke variabele was het niet behalen van de propedeuse na 2 jaar. Als onafhankelijke variabelen zijn meegenomen: aantal credits, aantal tentamenpogingen, tentameneffectiviteit (aantal behaalde credits/aantal pogingen) en instroomkenmerken als geslacht, leeftijd, gemiddeld eindexamencijfer en een niet-Nederlandse vooropleiding.

Vervolgens is voor 912 studenten met minder dan het maximale aantal credits na 3 tentamens (students-at-risk) de voor- 
spelling op basis van het model afgezet tegen het resultaat na 2 jaar. De vier resulterende groepen (true positives, false positives, true negatives en false negatives) zijn vergeleken op zowel instroomkenmerken als studeergedrag en studieprestaties op verschillende tijdstippen tijdens de eerste twee jaar. Hiervoor is gebruik gemaakt van parametrische (ANOVA) en nonparametrische testen (Chi-kwadraat; KruskalWallis).

Resultaten: De belangrijkste voorspellers voor uitval waren 'minder dan 19 credits (maximum) na 3 tentamens' en '0 credits op tentamens 4 en 5'. Studenten die voldeden aan beide criteria hadden een kans van 0.63 om uit te vallen, terwijl voor studenten met hetzij minder dan 19 credits na 3 tentamens hetzij 0 credits op tentamen 4 en 5, de kansen respectievelijk 0.12 en 0.10 waren. Met deze variabelen in het model konden we na zes maanden studie $90.0 \%$ van de studenten correct classificeren; specificiteit en sensitiviteit waren respectievelijk $94.0 \%$ en $63.9 \%$.

De vier groepen students-at-risk ( $\mathrm{n}=91$ 2) verschilden op alle instroomkenmerken en op alle indicatoren van studeergedrag en studieprestaties significant van elkaar $(\mathrm{p}<0.001)$. Drie types kunnen onderscheiden worden: redelijk succesvolle studenten met een trage start (74.6\%), studenten die weinig pogingen doen en weinig succes hebben $(16.9 \%)$ en studenten die veel pogingen doen en toch weinig succes hebben $(8.5 \%)$.

Discussie: Ons onderzoek suggereert dat instroomkenmerken en gegevens over studeergedrag en studieprestaties kunnen helpen bij het identificeren en karakteriseren van students-at-risk, maar dat er grote verschillen bestaan binnen deze groep op bovengenoemde kenmerken. Toekomstig onderzoek dient zich te richten op het nader onderscheiden van de subgroepen met behulp van additionele factoren (bijv. motivatie, aanpassingsvermogen) en op het uittesten van verschillende interventieprogramma's.

\section{Literatuur}

1. Arulampalam W, Naylor R, Smith J. Factors affecting the probability of first year medical student dropout in the UK: a logistic analysis for the intake cohorts of 1980-92. Medical Education 2004;38:492-503.

2. Murtaugh PA, Burns LD, Schuster J. Predicting the retention of medical students. Research in Higher Education 1999; 40(3):355-371.

Correspondentieadres:

K.M. Stegers-Jager, Erasmus MC, Opleidingsinstituut Geneeskunde, kamer Ff 2.11. Postbus 2040, 3000 CA Rotterdam

Longitudinale klinische beoordelingen en competentiegroei: een betrouwbaarheidsstudie

M.T. van Lohuizen, J.B.M.Kuks, E.A. van Hell, R.E. Stewart, J. Cohen-Schotanus

Probleemstelling: Om tot een betrouwbaar eindoordeel van een student te komen, moet deze meerdere malen beoordeeld worden. ${ }^{1}$ Met een betrouwbaarheidsstudie kan worden vastgesteld hoeveel beoordelingen nodig zijn voor een betrouwbaar eindoordeel. Bij betrouwbaarheidsstudies over klinische beoordelingen is steeds onderscheid gemaakt tussen (gewenste) variatie in scores veroorzaakt door verschillen tussen studenten en alle overige variatiebronnen, zoals docenten en casusspecificiteit. Echter, bij longitudinale beoordelingen zou ook rekening gehouden moeten worden met verwachte groei in competentie gedurende de periode van beoordelen. ${ }^{2} \mathrm{De}$ variatie in scores veroorzaakt door deze groei (eindscores hoger dan beginscores) kan als gewenste variatie worden beschouwd. In deze studie is nagegaan welke invloed het rekening houden met 
de competentiegroei heeft op de betrouwbaarheid van longitudinale klinische beoordelingen.

Methode: De coschapbeoordelingen van 104 coassistenten $(75 \%)$ die toestemming hadden gegeven voor gebruik van hun scores zijn verzameld. Elke coassistent is gedurende een periode van 14 weken 5-7 keer beoordeeld met een op de mini-CEX gebaseerde lijst; het eindoordeel is het rekenkundig gemiddelde. De coassistenten waren afkomstig uit alle disciplines in het UMC en 6 affiliaties. De betrouwbaarheid van de eindbeoordelingen werd geschat met generaliseerbaarheidsstudies, eerst volgens de standaardaanpak en daarna rekening houdend met competentiegroei. De volgende variantiecomponenten werden onderscheiden: verschillen tussen studenten, competentiegroei binnen studenten (alleen tweede analyse) en overige factoren (ruis). Aangezien de beoordelingen 'genest' waren binnen studenten zijn de variantiecomponenten geschat met multilevel analyse (G-studie). De betrouwbaarheid is vervolgens berekend voor verschillende aantallen beoordelingen en er is onderzocht hoeveel beoordelingen nodig zouden zijn om een betrouwbaarheid van 0.80 te behalen ( $\mathrm{D}$-studie).

Resultaten: Gemiddeld werd op de eerste beoordeling 7.6 gescoord en op de laatste $7.8(\mathrm{p}<0.05)$. Tabel 1 geeft de betrouwbaarheidscoëfficiënten voor beide situaties. Wanneer er rekening wordt gehouden met groei, daalt het aantal beoordelingen dat nodig is om een betrouwbaarheid van 0.80 te bereiken van 17 naar 11 .
Discussie: Dat er sprake is van competentiegroei blijkt uit het feit dat de eerste beoordeling van de studenten significant lager was dan de laatste. Deze bevinding is ook elders gerapporteerd. ${ }^{2}$ Het aantal beoordelingen dat volgens de standaardaanpak nodig is, ligt hoger dan wat in eerder onderzoek werd gerapporteerd. ${ }^{1} \mathrm{Re}$ kening houden met competentiegroei leidt tot een lagere aantal benodigde beoordelingen. Echter, 11 beoordelingen is voor de praktijk nog steeds aan de hoge kant. Een mogelijk oplossing zou zijn alle beoordelaars te instrueren te beoordelen naar een vast eindpunt. ${ }^{2}$ Nader onderzoek is nodig om te zien of dergelijke instructie de variatie veroorzaakt door competentiegroei, beter zichtbaar maakt en dit daarmee de betrouwbaarheid ten goede komt. De huidige 5-7 beoordelingen zijn in ieder geval niet genoeg om een betrouwbaarheid van 0.80 te bereiken.

\section{Literatuur}

1. Williams RG, Klamen DA, McGaghie WC. Cognitive, social and environmental sources of bias in clinical performance ratings. Teach Learn Med 2003;5(4);270-292

2. Prescott-Clements L, Van der Vleuten CPM, Schuwirth LWT, Hurst Y, Rennie JS. Evidence for validity within workplace assessment: the Longitudinal Evaluation of Performance (LEP). Med Educ 2008;42;488-95

Correspondentieadres:

Drs. M.T. van Lohuizen, UMCG/RUG, CIOMO, A. Deusinglaan 1, 9713 AV Groningen.

E-mail:m.t.van.lohuizen@med.umcg.nl

Tabel 1. Geschatte betrouwbaarheid van klinische beoordelingen.

\begin{tabular}{|c|c|c|c|c|c|c|c|c|c|c|}
\hline Aantal beoordelingen & 1 & 2 & & 5 & 6 & 7 & & 11 & & 17 \\
\hline standaard aanpak & 0.19 & 0.32 & $\ldots$ & 0.54 & 0.58 & 0.62 & $\ldots$ & 0.72 & $\ldots$ & $>0.8$ \\
\hline competentiegroei & $x$ & 0.50 & & 0.65 & 0.68 & 0.72 & & $>0.8$ & & 0.90 \\
\hline
\end{tabular}




\section{Genomineerde Papers}

\section{Effectiviteit van nascholing voor huisarts- opleiders: medische en didactische inhoud gecombineerd}

\section{A. Karg, P.M. Boendermaker, P.L.P. Brand, J. Cohen-Schotanus}

Probleemstelling: Nascholingscursussen voor artsen worden tot nu toe gescheiden georganiseerd op medisch of didactisch gebied. Huisartsopleiders moeten voor beide gebieden accrediteren. Een gecombineerde cursus zou hen tijd en geld besparen. Het is echter van belang te weten of een dergelijke combinatie ook effectief is. Effectiviteit van cursussen kan volgens Kirkpatrick door verandering op vier niveaus worden gemeten: reactie, leren, gedrag en procesuitkomsten. ${ }^{1}$ In dit onderzoek wordt effectiviteit van een gecombineerde nascholing op het derde niveau gemeten. De uitkomstmaat is gedragsverandering van deelnemers op medisch en didactisch gebied.

Methode: Deelnemers waren ervaren en onervaren huisartsopleiders. De meting werd bij zes groepen gedaan $(n=182)$. In de 2x2-daagse nascholing werden de volgende acht onderwerpen gecombineerd: algemene psychopathologie, angststoornissen, persoonlijkheidsstoornissen, verslavingszorg (medisch) met Leary's roos, beoordeling van HAIO's, video-opnames maken, vermijdingsgedrag van HA-opleiders (didactisch). Op de laatste dag moes- ten alle deelnemers aangeven wat zij van plan waren in de praktijk te implementeren (lijst 1). Twee maanden na de cursus kregen de deelnemers hun ingevulde lijst 1 thuisgestuurd met de vraag 'Welke plannen hebt u geïmplementeerd?' (lijst 2). De antwoorden op de open vragen werden door twee onderzoekers gecodeerd voor kwantitatieve analyse. Consensus werd bereikt door discussie. Bij de analyse werd gebruik gemaakt van de gepaarde t-toets en de $\mathrm{Chi}^{2}$-toets.

Resultaten: De 182 deelnemers gaven op lijst 1 in totaal 384 plannen op. Lijst 2 werd door 127 respondenten (70\%) teruggestuurd. Daarop werden van de 266 oorspronkelijke plannen 168 (63\%) als geïmplementeerd aangegeven door 113 respondenten $(89 \%)$ - zie tabel 1 .

Op medisch gebied werd 'angststoornissen’ ( $n=26$ lijst 1 ) het vaakst als plan opgegeven. Op didactisch gebied was dat 'Leary's roos' ( $\mathrm{n}=109$ lijst 1). In alle groepen werden significant meer didactische dan medische plannen aangegeven (deelnemers $\mathrm{n}=182 ; \mathrm{t}=15.6$; $\mathrm{p}<0.05$; respondenten $\mathrm{n}=127 ; \mathrm{t}=14.52 ; \mathrm{p}<0.05$; niet-respondenten $\mathrm{n}=55 ; \mathrm{t}=6.79 ; \mathrm{p}<0.05)$. Van de plannen op medisch gebied werd 54\% geïmplementeerd, op didactisch gebied was dit $65 \%$ - zie tabel. Dit verschil was niet significant $\left(\mathrm{Chi}^{2}=5,28 ; \mathrm{p}=0.26\right)$.

Conclusies en Discussie: Op basis van de resultaten kan de gecombineerde nascholing als effectief worden beschouwd: $89 \%$ van de respondenten gaf aan dat hun dagelijkse praktijk door de cursus is ver-

Tabel 1.

\begin{tabular}{ll|lll}
\hline & personen & Plannen totaal & medisch & didactisch \\
\hline lijst 1 & 182 & 384 & 82 & 302 \\
lijst 2 & 127 & 266 & 52 & 214 \\
geïmplementeerd & 113 & 168 & 28 & 140 \\
\hline
\end{tabular}


anderd. De resultaten zijn vergelijkbaar met medische nascholing, waarbij zelfrapportage daadwerkelijke gedragsveranderingen voorspelde. ${ }^{2}$ Het lijkt dat de effectiviteit groter is op didactisch gebied. Uit nadere analyse van lijst 2 bleek echter dat respondenten sommige didactische onderwerpen (voornamelijk 'Leary's roos') ook in medische context hebben toegepast. Dit is waarschijnlijk het effect van de gecombineerde aanpak. Vervolgonderzoek moet uitwijzen welke factoren de plannen en implementatie bij een gecombineerde nascholing beïnvloeden.

\section{Literatuur}

1. Kirkpatrick, DL. Great ideas revisited. Training and development. 1996 jan;50(1):54-9

2. Wakefield J, Herbert CP, Maclure M, Dormuth C, Wright JM, Legare J, Brett-MacLean P, Premi J. Commitment to change statements can predict actual change in practice. J Contin Educ Health Prof. 2003 Spring;23(2):81-93.

Correspondentieadres:

Drs. A. Karg, UMC Groningen, A. Deusinglaan 1, 9713 AV Groningen.E-mail: a.karg@med.umcg.nl

De visie van opleiders, arts-assistenten en patiëntenverenigingen ten aanzien van het patiëntveiligheidsklimaat en -onderwijsbehoeften

\section{J.D. Jansma, A.B. Bijnen, C. Wagner}

Probleemstelling: Uit onderzoek is gebleken dat jaarlijks een groot aantal patiënten slachtoffer wordt van vermijdbare schade in het zorgproces. Dit heeft geresulteerd in een toename van de aandacht voor patiëntveiligheid en het treffen van maatregelen om deze te verbeteren. Hoewel menselijke factoren de voornaamste veroorzakers zijn van incidenten, wordt specifiek op veiligheid gericht onderwijs nauwelijks opgenomen als speerpunt in veiligheidsmanagementbeleid. Arts-assis- tenten zijn hiervoor een belangrijke doelgroep, omdat zij dicht aan het bed van patiënten staan en de specialisten van de toekomst zijn. Het huidige onderzoek tracht inzicht te verschaffen in visies van arts-assistenten en twee belangrijke andere stakeholders, namelijk opleiders en patiëntenverenigingen, ten aanzien van het patiëntveiligheidsklimaat en -onderwijsbehoeften.

Methode: Door een expertgroep zijn open en gesloten vragen ontwikkeld. Deze richten zich onder meer op hoe veilig men de huidige patiëntenzorg acht, wat men vindt bijdragen aan patiënt(on)veilige situaties en wat men belangrijk acht voor patiëntveiligheidsonderwijs voor artsassistenten. In mei 2007 is de vragenlijst zowel in papieren, als in digitale vorm verzonden aan leden van de centrale opleidingscommissie $(n=46)$ en arts-assistenten ( $\mathrm{n}=137)$ van het Medisch Centrum Alkmaar. Daarnaast hebben 16 patiëntenverenigingen de vragenlijst ontvangen.

Resultaten: In totaal hebben 25 (54\%) opleiders, $92(67 \%)$ arts-assistenten en $8(50 \%)$ patiëntenverenigingen de vragenlijst ingevuld geretourneerd. Uit analyses is naar voren gekomen dat arts-assistenten de patiëntenzorg veiliger vinden dan opleiders ( $\mathrm{p}=0.036)$. Hoge werkdruk en gebrekkige communicatie zijn door zowel arts-assistenten, als opleiders genoemd als voornaamste factoren die bijdragen aan patiëntonveilige situaties. Door patiëntenverenigingen is naast gebrekkige communicatie, het niet goed luisteren naar de patiënt als patiëntonveilig aspect naar voren gekomen. Arts-assistenten vinden het belangrijk dat in patiëntveiligheidsonderwijs aandacht besteed wordt aan problemen waar zij in de praktijk tegen aanlopen zoals 'Wat mag ik tegen een patiënt zeggen bij een fout?' en 'Wat kunnen we leren van gemaakte fouten?' Opleiders lijken meer te redeneren vanuit het besef 
dat arts-assistenten zich in een leerproces bevinden en feilbaar zijn. Zij vinden het bewustmaken van de eigen beperkingen en het belang van protocollen belangrijke onderwerpen voor patiëntveiligheidsonderwijs. Patiëntenverenigingen benadrukken het belang dat arts-assistenten bewuster de patiënt centraal leren stellen en meer vanuit het patiëntenperspectief leren redeneren en dat zij daarnaast hun beperkingen kennen en daar adequaat mee om leren gaan.

Discussie: Door middel van enquêtes is inzicht verkregen in opvattingen over het heersende veiligheidsklimaat en behoeften omtrent patiëntveiligheidsonderwijs bij drie belangrijke stakeholders. De bevinding dat arts-assistenten de veiligheid van de zorg hoger inschatten dan opleiders wijst erop dat het veiligheidsbesef van de jonge arts verder ontwikkeld dient te worden en bekrachtigt de noodzaak van onderwijs omtrent dit onderwerp. De uitkomsten van dit onderzoek hebben een belangrijke rol gespeeld bij de keuze van kernthema's binnen het patiëntveiligheidsonderwijs, zoals patiëntveilige communicatie, het herkennen van onveilige situaties en het belang van een open cultuur.

Correspondentieadres:

J.D. Jansma, MSc, Medisch Centrum Alkmaar/EMGO Instituut Wilhelminalaan 12, 1815 JD Alkmaar. E-mail:j.d.jansma@mca.nl

Extracurriculair 'peer-to-peer' anatomieonderwijs; een onderwijsmodel voor de toekomst? (tussentijdse evaluatie)

\section{H.P. Theeuwes, J.F. Lange, G.J.E. Kleinrensink}

Inleiding: De tendens tot vermindering van het anatomieonderwijs in Europa en de VS heeft geleid tot een verschraling van de anatomische kennis onder aankomend artsen. Gepoogd is studenten te enthou- siasmeren en het klinisch belang van de anatomie in te laten zien. Om dit te kunnen bereiken is ervoor gekozen studenten zelf anatomisch onderwijs te laten verzorgen voor hun collega-studenten, het zogenaamde 'peer to peer' teaching model. De invulling hiervan is geheel aan de studenttutoren overgelaten en vormt hiermee de basis voor het onder beschreven project.

Methode/opzet: Het betreft een vijfjarig project met als doelen 1) een 'student anatomie sectie' op te richten, 2) het opnieuw onder de aandacht brengen van de klinische noodzaak van anatomie, 3) als kweekvijver te fungeren voor aanstormend talent en 4) een bijdrage te leveren aan de 'community building' binnen de faculteit. 272 studenten uit voornamelijk de doctoraalfase namen, na selectie, acht weken lang een avond in de week deel aan een extracurriculair anatomiepracticum (ErasmusMC Anatomy Research Project, EARP) dat plaats vond na college-uren. Tijdens dit project worden diverse competenties gestimuleerd. De practica worden door 8 tutoren en 16 assistenten pro deo voorbereid en uitgevoerd, hieronder vallen o.a. dissectiehandleidingen schrijven en het organiseren van lezingen door specialisten. De tutoren verzorgen zelf de werving en selectie van hun opvolgers en garanderen zodoende de continuïteit en kwaliteit van het project. Naast onderwijs is er ook ruimte voor klinisch- anatomisch onderzoek dat met name door de tutoren wordt uitgevoerd. $\mathrm{Na}$ afloop van elk jaar is er een evaluatie-enquête ingevuld door de deelnemers.

Evaluatie: Na drie jaar lijkt er duidelijk meer belangstelling te zijn voor extra anatomisch onderwijs, wat zich uit in een toename van het aantal inschrijvingen en aanvragen. Doelen 1 t/m 4 zijn grotendeels behaald. Het overgrote deel van de deelnemende studenten (80-90\%) ervaart het project als een zeer waardevolle aanvulling en voorbereiding op de co-schap- 
pen. De impact van de toegepaste anatomie als basis voor het medisch handelen is zowel bij studenten als organisatie sterk vergroot.

Conclusie: Het lijkt mogelijk een 'student anatomie sectie' op te richten die het belang van anatomische kennis en vaardigheden onder de aandacht van de eigen groep kan brengen en houden. Het gevoel bij een groep enthousiaste 'doeners' te horen heeft een zeer positief effect op de sfeer binnen de relatief anonieme entourage op de faculteit. Door het autonome 'peer to peer' karakter van dit project is vanuit de faculteit weinig investering in personeel en middelen nodig. De haast ongelimiteerde inzet en het enthousiasme van deze anatomie sectie lijken fundamenteel voor dit succes.

Correspondentieadres:

Drs. H.P. Theeuwes, Erasmus MC, postbus 2040, 3000 CA Rotterdam.E-mail: hilcotheeuwes@gmail.com

Interbeoordelaarsbetrouwbaarheid tussen simulatiepatiënten en tussen simulatiepatiënten en artsen bij een objective structured clinical examination (OSCE)

\section{E.A.M. Pelgrim, A.M. Hettinga, C.T. Postma}

Probleemstelling: De nieuwe assessmentprocedure voor artsen van buiten de Europese Unie, geïmplementeerd in december 2005, bestaat uit verschillende deeltoetsen. De deeltoets klinische vaardigheden bestaat uit een OSCE met 10 toetsstations waarbij de kandidaten een geheel consult verrichten en beoordeeld worden op anamnese, lichamelijk onderzoek, communicatie, professioneel gedrag en schriftelijke verslaglegging. De simulatiepatiënten worden intensief getraind in deze beoordeling. Hoewel in de literatuur beschreven wordt dat simulatiepatiënten getraind kunnen worden om kandidaten te scoren, is er nog steeds twijfel en discussie of simulatiepatiënten bij belangrijke examens kunnen scoren. Om de kosten van dergelijke toetsen te beheersen is het van groot belang dit verder te onderzoeken. De onderzoeksvraag die wij stellen is: Wat is de overeenstemming in beoordeling tussen een spelende simulatiepatiënt en een observerende simulatiepatiënt? En wat is de overeenstemming in beoordeling tussen een spelende simulatiepatiënt en een observerende arts?

Methode: De spelende simulatiepatiënt en de beoordelaar geven op een checklist aan of de kandidaat relevante gegevens uit de anamnese heeft besproken. Op de checklist kan 'ja' of 'nee' worden aangegeven door de beoordelaars. Bij het lichamelijk onderzoek kunnen de beoordelaars aangeven of een onderzoek adequaat, inadequaat of niet is uitgevoerd. Van de 22 stations zijn met betrekking tot de anamnesevaardigheden gegevens beschikbaar van 469 dubbel gescoorde kandidaten. Bij het lichamelijk onderzoek is $266 \mathrm{keer}$ dubbel gescoord. Bij beide onderdelen was 17 keer een arts betrokken bij de beoordeling. Om de interbeoordelaarsbetrouwbaarheid te bepalen wordt de kappa-coëfficiënt $(\mathrm{K})$ berekend (De Vocht, 2005). Bij een $\mathrm{K}$ groter dan 0.75 is er sprake van een grote mate van overeenstemming. Bij een $\mathrm{K}$ tussen 0.40 en 0.75 is er een redelijke tot goede overeenstemming. Waarden van minder dan 0.40 duiden op een zwakke overeenstemming.

Resultaten: Analyse op anamnesevaardigheden laat een kappa-coëficiënt van 0.777 zien. Van de 469 dubbele beoordelingen zijn 452 kandidaten beoordeeld door twee simulatiepatiënten. De kappa van deze beoordelingen bedraagt 0.779 . De overige 17 kandidaten zijn door een arts en een simulatiepatiënt beoordeeld. Bij deze 17 beoordelingen bedraagt de kappa 0.720 . 
Conclusie: Er is sprake van een grote mate van overeenstemming tussen de beoordelaars. De overeenstemming bij beoordelingen door een simulatiepatiënt en een arts valt iets lager uit, maar is nog steeds redelijk tot goed.

Discussie: De beoordelaarsovereenstemming is hoog genoeg om simulatiepatiënten te laten beoordelen tijdens belangrijke examens. De hogere overeenstemming tussen simulatiepatiënten onderling zou het effect kunnen zijn van de regelmatigere basis waarop de simulatiepatiënten scoren in vergelijking met de arts. Om de kosten van grootschalige toetsing beheersbaar te houden is het wenselijk dat simulatiepatiënten scoren tijdens vergelijkbare toetsen.

\section{Literatuur}

1 Vocht, A., de (2005). Basishandboek SPSS 13 voor windows. Utrecht: Bijleveld Press.

2. Whelan GP, Boulet JR, McKinley DW, Norcini JJ, van Zanten M, Hambleton RK, Burdick WP Peitzman SJ. Scoring standardized patient examinations: lessons learned from the development and administration of de ECFMG Clinical Skills Assessment. Medical Teacher (2005) May;27(3): 200-6

\section{Correspondentieadres:}

E.A.M. Pelgrim, UMC St Radboud, Onderwijsinstituut, Huispostnummer 306, postbus 9101, 6500 HB Nijmegen.E-mail:e.pelgrim@owi.umcn.nl

\section{Genomineerde Posters}

Leren over grenzen: De SSART, een wereldwijd gebruikte screening op slikstoornissen aangepast voor gebruik in ontwikkelingslanden.

M. Tepper, R.T. deVries, F.M.L. Donderwinkel, E. Aris

Introductie: Ontwikkelingslanden staan voor de grote uitdaging het stijgende aantal doden ten gevolge van welvaartziekten een halt toe te roepen. Hierdoor zal er een toenemende vraag zijn naar onderwijsprogramma's gewijd aan welvaartziekten. Het introduceren van wereldwijd geaccepteerde Evidence Based protocollen in ontwikkelingslanden kan grote problemen opleveren. Voor implementatie moet het protocol worden aangepast aan de mogelijkheden binnen de landelijke gezondheidszorg en aan de gangbare culturele gebruiken. De kans op een succesvolle implementatie van het protocol kan verhoogd worden door gebruik te maken van al ter plaatse aanwezige kennis en het gebruik van lokaal favoriete leermethoden binnen het aangeboden scholingsprogramma.

Een aangepaste gestandaardiseerde screening op slikstoornissen (SSART: Standardized Swallowing Assessment Rehabilitation Tanzania) werd in het kader van een scholingsprogramma betreffende slikstoornissen bij CVA-patiënten geïntroduceerd in het Muhimbili National Hospital te Dar es Salaam, Tanzania.

Methode: $\mathrm{Na}$ een literatuurstudie werd de Standardized Swallowing Assessment (SSA) van Perry gecombineerd met het protocol van Westergren betreffende diagnostiek van slikstoornissen en eetproblemen bij CVA patiënten tot een SSA RehabilitationTanzania. In de SSART is het consulteren van een logopediste vervangen door een overleg van verpleegkundige met de afdelingsarts. De benodigde middelen voor de test (kopje en theelepeltje) zijn overal in Tanzania voorradig.

Implementatie: Er deden 57 ervaren verpleegkundigen en 3 fysiotherapeuten van het Muhimbili National Hospital mee aan een scholingsprogramma betreffende slikstoornissen en eetproblemen bij CVApatiënten. De fysiotherapeuten werden als docenten ingezet tijdens de lessen 'omdraaien in bed' en 'van lig naar zit'. Een testmaaltijd met 'local food' werd door de deelnemers samengesteld. Aan het eind 
van de cursus werd door de deelnemers met behulp van rollenspellen een samenvatting van het geleerde gegeven.

Conclusie: The SSART is een aangepast protocol voor slikstoornissen en eetproblemen. Er is geen logopediste noodzakelijk, het gebruikte testmateriaal is aanwezig en lokaal aanwezige voeding is geïmplementeerd als testmaaltijd in het protocol.

Dit aangepaste protocol kan eenvoudig in andere ontwikkelingslanden worden geïmplementeerd in de dagelijkse routine waar logopedistes niet werkzaam zijn in ziekenhuizen. Echter het scholingsprogramma moet worden aangepast aan culturele omstandigheden en lokaal favoriete leermethodes moeten onderdeel uitmaken van het programma.

Correspondentieadres:

Drs. M. Tepper, UMC Groningen, Centrum voor revalidatie, Hanzeplein 1, 9700 RB Groningen.

E-mail:m.tepper@rev.umcg.nl

Ontwikkeling van een vragenlijst Professioneel Gedrag voor studenten

\section{J. Prins, M. Nuijten}

Probleemstelling: Onderwijs professioneel gedrag in de opleiding geneeskunde vindt plaats op basis van de eindtermen in het Raamplan en CanMEDS. Doel is kwaliteitsverbetering en standaardisering van de medische zorg door competentieleren, niet alleen op het niveau van kennis, opvattingen en vaardigheden, maar ook op observeerbaar professioneel gedrag in de medische praktijk. Het effect van onderwijs professioneel gedrag op professioneel gedrag van studenten is nog nauwelijks onderzocht bij gebrek aan adequate meetinstrumenten. Doel van dit onderzoek was het ontwikkelen van een betrouwbare en valide vragenlijst over professioneel ge- drag, die geschikt is voor herhaalde meting bij studenten in zowel de bachelorals masterfase.

Methode: Noodzakelijke stappen in de ontwikkeling van een betrouwbare en valide vragenlijst werden gevolgd. ${ }^{1} \mathrm{Bij} 42$ eindtermen in het Raamplan ${ }^{2}$ vermeld in de categorie Persoonlijke aspecten (artspatiënt relatie, persoonlijk functioneren, wederzijdse beïnvloeding werk-privéleven) werden zes beschrijvingen van gedrag van artsen gemaakt. Deze werden op bruikbaarheid beoordeeld door twee docenten professioneel gedrag met als doel reductie tot twee beschrijvingen per eindterm (bevestigende en ontkennende formulering), die op een 5-punts schaal (helemaal oneens - helemaal eens) beoordeeld kunnen worden. Vervolgens werd de vragenlijst met 84 items voorgelegd aan 148 tweedejaarsstudenten geneeskunde. Tevens werd de vragenlijst voorgelegd aan docent-mentoren die professioneel gedrag van studenten beoordelen. Met statistische analyses van de interne consistentie werd de betrouwbaarheid van de vragenlijst bepaald. Correlaties tussen studenten en docenten werden gebruikt om tot een verantwoorde keuze van relevante items te komen. Op basis van deze gegevens vond verdere reductie tot één gedragsbeschrijving per eindterm plaats.

Resultaten: Het testontwikkelingsonderzoek resulteerde in een vragenlijst professioneel gedrag voor studenten met een goede interne consistentie (Cronbach alpha >.80). De 42 items hebben voldoende spreiding (min. 1-3 tot max. 4-5) en range (2.48-4.6) om te kunnen differentiëren tussen studenten en ontwikkeling te laten zien. De statistische gegevens zullen gepresenteerd worden.

Discussie: De vragenlijst voor studenten met 42 beschrijvingen van professioneel gedrag, corresponderend met relevante eindtermen, lijkt een betrouwbaar en valide 
instrument om de ontwikkeling van professioneel gedrag van studenten gedurende de opleiding geneeskunde te meten. De vragenlijst bevat zowel gedragsbeschrijvingen met een bevestigende als ontkennende formulering om het risico van sociaal wenselijk antwoorden te reduceren. Nader onderzoek bij studenten zal moeten uitwijzen in welke mate de opvattingen over de (toekomstige) beroepsuitoefening corresponderen met feitelijk gedrag en in hoeverre de vragenlijst geschikt is om voorspellingen te doen over (on)professioneel gedrag van studenten.

\section{Literatuur}

1. Drenth PJD. Inleiding in theorie van de psychologische test en zijn toepassingen. Bohn Stafleu Van Loghum 2006.

2. Metz JCM, Verbeek-Weel AMM, Huisjes HJ. Raamplan 2001 artsopleiding. Bijgestelde eindtermen van de artsopleiding. UMC Nijmegen 2001.

Correspondentieadres:

Dr. J.B. Prins UMC St Radboud, Medische Psychologie, postbus 9101, $6500 \mathrm{HB}$ Nijmegen.

E-mail:j.prins@mps.umcn.nl

Vorming van een Academicus in het Erasmus $M C$

\section{E.J. Spierenburg, A.M. van Meeuwen, E.F. van Beeck}

Probleemstelling: Om verschillende redenen (zoals de vergankelijkheid van medische kennis, de noodzaak tot reflectie op het eigen handelen en de dynamiek van de samenleving) wordt het afleveren van artsen met een academisch werk- en denkniveau door het Erasmus MC van groot belang geacht. In het huidige curriculum worden de eindtermen van het Raamplan op dit punt niet gehaald.

Methode: Een projectgroep, samengesteld uit artsen, (gezondheids)wetenschappers en beleidsadviseurs, heeft een voorstel geformuleerd voor versterking van het academisch karakter van het curriculum Erasmusarts, zodat minimaal de eindtermen van het raamplan worden behaald. Dit voorstel wordt met ingang van het collegejaar 2008-2009 stapsgewijs ingevoerd in de nieuwe bachelor-masterstructuur.

Resultaten: Academische vorming wordt op drie niveau's in het curriculum geïmplementeerd:

1) door inpassing in bestaand onderwijs. Door het expliciet stellen van 'academische' vragen aan studenten wordt academische vorming op natuurlijke wijze onderdeel van het onderwijs. Ter ondersteuning en inspiratie is hiervoor een boekje samengesteld met de beste academische voorbeelden uit het eigen curriculum. Daarnaast is een workshop ontwikkeld waarin docenten actief hun eigen onderwijs kunnen doorlichten op het academische gehalte ervan.

2) door aanbod van nieuw, verplicht, onderwijs.

In alle bachelorjaren en het eerste masterjaar participeren studenten een aantal keer per jaar in een journal club, waarin wetenschappelijke artikelen worden besproken en maken zij schrijfopdrachten die beoordeeld worden op redeneervaardigheden. Tevens wordt tijdens deze studiejaren nieuw onderwijs toegevoegd, waarin medische ethiek, medische filosofie, medische besliskunde, medische geschiedenis en gezondheidsrecht centraal staan. Hierdoor wordt de aandacht voor reflectie op de geneeskunde substantieel uitgebreid.

In het derde bachelor jaar volgen studenten een minor van 10 weken, welke ook kan worden ingevuld met het kiezen van een vakgebied buiten de geneeskunde 
Tijdens de grote co-schappen in het tweede en derde jaar van de masterfase worden zogenaamde Evidence Based Medicine (EBM) clubs ingevoerd. Vooraf aan deze bijeenkomsten werken co- assistenten een zelfgekozen klinisch probleem uit volgens een EBM-aanpak.

Naast de beoordeling van de presentatievaardigheden in de journalclubs maken studenten in het tweede bachelor jaar een toets waarin ze aan de hand van een wetenschappelijk artikel vragen beantwoorden. De bachelorfase sluit af met een toets waarin studenten een stuk moeten schrijven waarin ze worden beoordeeld op hun redeneervaardigheden.

3) door het overzichtelijk aanreiken van extracurriculair aanbod.

Via één startpagina op de website van de Erasmusarts wordt een overzicht geboden van het aanbod aan lezingen, voorstellingen, en overige bijeenkomsten die kunnen bijdragen aan de academische vorming van een individuele student.
Conclusie: In het nieuwe Bama curriculum van het Erasmus MC zal systematisch aandacht worden besteed aan academische vaardigheden, zoals het kritisch beoordelen en het gebruik van wetenschappelijke literatuur, het logisch redeneren, het helder schrijven en een reflectie op de geneeskunde. Er is een checklist ontwikkeld, waarmee de projectgroep op grond van jaarlijkse evaluaties kan vaststellen of het beleid ook daadwerkelijk wordt geïmplementeerd en tot welke resultaten dit leidt.

Correspondentieadres:

Drs. E.J. Spierenburg, Erasmus MC, Opleidingsinstituut Geneeskunde, postbus 2040, 3000 CA Rotterdam. E-mail:e.spierenburg@erasmusmc.nl 